\title{
Long lasting time outdoor atmospheric corrosion tests
}

\author{
M. Leiro ${ }^{1} \&$ E. S. Ayllón ${ }^{2}$ \\ ${ }^{I}$ Department of Corrosion Science, \\ (Departamento Investigaciones en Corrosión), CITEFA, Argentina \\ ${ }^{2}$ Department of Material Science and Technique, \\ (Departamento Ciencia y Técnica de Materiales), CITEFA, Argentina
}

\begin{abstract}
Since its introduction in 1933, the concept of patinas as a corrosion controlling mechanism has been playing an important role in many structural applications. The analysis of the initial stages of the corrosive attack showed that this phenomenon, which was considered uniform at first, is actually a moderate one being the non-metallic inclusions in structural steels, the preferred points of attack.

Long-lasting tests were carried out in the urban site of Villa MartelliArgentina outdoor tests station. Specimens were obtained from a hot-rolled structural steel sample of $3.5 \mathrm{~mm}$ thickness, $45 \mathrm{~mm}$ wide and $300 \mathrm{~mm}$ long. The outdoor tests were carried out over 35 years. The results were obtained by optical microscopy, electron scanning, and electron probe microanalysis showing that the addition of microalloyed elements modifies steel behaviour. This modification means a steel increase resistance towards atmospheric corrosion.
\end{abstract}

\section{Introduction}

The term 'weathering steels' describes a class of low-alloy structural steels that develop an adherent protective rust layer, called patina, during exposure to the atmosphere As a result of this, weathering steels, unlike ordinary plain carbon steels, do not require painting, which means important advantages: avoiding associated costs of initial painting, periodic repainting, containment and disposal of blasting debris during repainting. 
Since the beginning of the study of atmospheric corrosion, it was considered basically as an electrochemical phenomenon. The analysis of the initial stages of the corrosive attack showed that this phenomenon which was considered uniform at first is actually a moderate one being the non-metallic inclusions in steels at the preferred points of attack. Evans electrochemical model for the atmospheric corrosion shows the reactions that explain the behaviour of corrosion products films as well as the influence of microalloying elements on the size of colloidal aggregates particles that form patinas. There have been many proposals to explain the protection mechanism. However, there seems to be no generally accepted theory up to now [1]. In the beginning of the research work there were two tendencies: the first one was to attribute the protective nature to the chemical characteristics of the present species, and the second one was to attribute the said protective nature to the morphology of the protective films. Many techniques were used for the patina characterization of corrosion products, which were formed because of being exposed to a natural environment. Non-metallic inclusions of $\mathrm{MnS}$ with or without $\mathrm{Fe}$ have a main role at the beginning of the corrosion process. Klund [2] determined that around the $\mathrm{MnS}$ inclusions there is an area, attributed to the steel cooling rate from its tapping temperature, following the inclusion contour. This is called MnS micro inclusions infected area, and is very reactive. While the $\mathrm{MnS}$ inclusion works as a cathodic area, the said infected area works as an anodic one. The progress of this process leaves the non-metallic inclusion without support to the steel matrix, and it is removed. Therefore, a whole or pit filled with corrosion products is originated and acts as an anodic area. Sometimes it is the inclusion itself the one that dissolves. This occurs when the inclusion has other chemical elements, which are easily attacked like the lanthanum.

Previous results verified by optical microscopy, electron scanning, and electron probe microanalysis showed that the addition of rare earths modifies steel behaviour towards atmospheric corrosion because of the different chemical composition of the non-metallic inclusions developed in the process.

Szummer and Janik-Czachor [3] point out that the presence of non-metallic inclusions, which were morphological modified by rare earths, is detrimental for corrosion resistance, and that the $\mathrm{CeS}$ attack nucleating effect is bigger than the $\mathrm{MnS}$ one, usually found in steels.

\section{Evan's electrochemical model}

Outdoor tests carried out during long periods of exposure have revealed that weathering steels (WS) with small additions of $\mathrm{Cu}, \mathrm{Cr}$, and $\mathrm{P}$ have much better atmospheric corrosion resistance than those steels without microalloying elements. Laboratory research by Poubaix [4] and Poubaix and de Miranda [5] has clearly shown that the said difference only occurs when steel samples are subject to repeated cycles of drying out and humidification. These tests like the ones carried out in a natural environment with a relative humidity always near saturation [6] have shown that there is no advantage in substituting ordinary steels for WS under the said environmental conditions. Many authors $[7,8]$ have 
pointed out the key influence of $\mathrm{Cu}$ as the most significant microalloying element to enhance atmospheric corrosion resistance, and they relate $\mathrm{Cu}$ to the formation of an inner denser and tightly adherent layer, which coats steel without cracks or defects. According to this, the tests carried out by Electron Probe Microanalysis (EPMA) [9] show that $\mathrm{Cu}$ concentrates mainly in those cavities resulting from the initial attack to nonmetallic inclusions, and in the space among them, which is in contact with steel. Infrared (IR) spectroscopy tests show that the main components of protective patinas are first the $\delta$ ferric oxyhydroxides $(\delta$ $\mathrm{FeOOH})$, called lepidocrocite, and then the $\alpha$ and $\beta$ oxyhydroxides and magnetite $\left(\mathrm{Fe}_{3} \mathrm{O}_{4}\right)$ in smaller amounts.

The reduction of the particle size resulting from an enrichment of $\mathrm{Cu}$ occurs with a reduction of the pores size and a greater tortuosity in the aggregate. According to Evans model, the reduction conditions exist in a big part of the film if the pores are filled with water (from rain or mist). However, the oxidation conditions prevail during the drying out periods. The balance between these two conditions moves to the steel during the drying out periods and to the atmosphere during the humidification periods.

The excellent atmospheric corrosion properties of WS cannot entirely be explained by the alloying elements. Although it seems, that the phosphorus in steel improves the atmospheric corrosion resistance, it seems also, that sulphur or sulphur oxides in air have an effect on protective patina formation on the steel.

Electrochemical curves show that the potential at which the maximum anodic current is produced, the oxidised element is now the $\mathrm{Fe}^{+2}$ intermediary in the surface of FeOOH globules instead of the magnetite [10]. Moreover, it would protect the patina inner layer due to an increase of its compactness, according to what is mentioned in the tests by Moroishi [9], Inouye [11] and Rosales [12]. Where there are neither microalloying elements or long humidification periods the a $\delta$-FeOOH would have been transformed into $\mathrm{Fe}_{3} \mathrm{O}_{4}$, because there is not controlling effect on the $\mathrm{Fe}_{3} \mathrm{O}_{4}$ production, which does not have a protective attribute, as reported by Kihira et al. [13].

\section{PA steel formulation}

According to what has been mentioned in previous works [14], the conclusion is that a formulation containing the necessary microalloying elements to produce the corrosion product film of a steel $(\mathrm{Cu}, \mathrm{Cr}$, and $\mathrm{Si})$ and non-metallic inclusions - modified by rare earths additions (particularly Ce) - is considered to join both criteria: weatherability and better mechanical properties.

Following these criteria, it was planned a weathering steel experimental tapping with the addition of rare earths as modifiers of non-metallic inclusions from their morphological as well as from their chemical reactivity point of view.

A minimum $\mathrm{C}$ content was planned to provide the mechanical strength and ferritic attribute of structural steels. The percentage of the main microalloying elements, $\mathrm{Cu}$ and $\mathrm{Cr}$, were fixed on practical basis. The available ferroalloys for steel production were considered as well as their use under the fusion conditions 
to be adopted. The recommendations given by specialised literature were used for the rare earths percentage and addition process to the ladle [15].

The percentage of Ni added -almost similar to the Cu's percentage- is the suggested one to neutralise the detrimental effect of the latter in the hot-rolled process, widely known as hot shortness. The vanadium - together with the aluminium - is a ferritic grain-refining agent. Due to its availability and easiness to operate, the rare earths silicide was adopted (Fe: 35\%; Si:31\%; and Rare Earths: $34 \%$; with a Ce composition of: $50 \%$; La:25\%; Nd: $10 \%$; and Pr:5\%) in a percentage of $1.0 \mathrm{~g} / \mathrm{kg}$ of melting steel as a means of containing these rare earths.

The chemical composition of steel -analysed in the hot-rolled product- in comparison with the one of the presently produced Cor Ten A and QST-52 nonalloyed steel is shown in Table 1.

Table 1: $\quad$ Chemical composition of hot-rolled PA steel, Cor Ten A steel and QST-52 non-alloyed steels used as a reference samples.

\begin{tabular}{|c|c|c|c|c|c|c|c|c|c|c|c|c|}
\hline Steel & $\mathbf{C}$ & $\mathbf{S i}$ & $\mathbf{M n}$ & $\mathbf{P}$ & $\mathbf{S}$ & $\mathbf{C u}$ & $\mathbf{C r}$ & $\mathbf{~ N i}$ & $\mathbf{A l}$ & $\mathbf{S n}$ & $\mathbf{A s}$ & $\mathbf{V}$ \\
\hline PA & 0.15 & 0.41 & 1.01 & 0.086 & 0.105 & 0.46 & 1.0 & 0.38 & 0.021 & 0.01 & 0.013 & 0.006 \\
Cor Ten & & & & & & & & & & & & \\
A & 0.10 & 0.36 & 0.34 & 0.093 & 0.018 & 0.31 & 0.60 & 0.12 & - & - & 0.005 & 0.008 \\
QST-52 & 0.16 & 0.36 & 1.36 & 0.013 & 0.035 & 0.05 & 0.07 & 0.06 & ----- & ---- & ------ & ----- \\
\hline
\end{tabular}

An induction furnace was used and 4 ingots of $60 \mathrm{~kg}$ net were tapped (without dead heads). The final temperature of the process after a careful bath deoxidisation by $\mathrm{Mn}, \mathrm{Al}$ and $\mathrm{Si}$ addition was of $1673^{\circ} \mathrm{C}$ in the furnace and of $1620^{\circ} \mathrm{C}$ in the ladle. The temperature of this process was between 1590 and $1600^{\circ} \mathrm{C}$.

After the tapping, the ingots were heated again at a rolling initial temperature of $1150^{\circ} \mathrm{C}$. The final rolling temperature was between $950-1000^{\circ} \mathrm{C}$. The final thickness was of $3.5 \mathrm{~mm}$ and the hardness was $283 \mathrm{H}_{\mathrm{B}}$. Upon completion of the rolling, the steel underwent a thermal treatment process to set the mechanical properties to the usually recommended ones under the Cor Ten A steel specifications (ASTM A-588 and A-242).

- Austenitised treatment: $\mathrm{T}=870 / 880^{\circ} \mathrm{C}$ for 10 minutes.

- Water cooling at room temperature.

- Tempering at $750^{\circ} \mathrm{C}$ for 1 hour.

- Cooling inside furnace up to $400^{\circ} \mathrm{C}$, then to the air.

- Final hardness of $\mathrm{H}_{\mathrm{B}}=160$, equal to a resistance to rupture of $53 \mathrm{~kg} \cdot \mathrm{mm}^{-2}$ (52 MPa).

\section{Open air exposure test}

Long-lasting tests were carried out in the urban site of Villa Martelli outdoor test station [16]. Specimens were obtained from the hot-rolled material of $3.5 \mathrm{~mm}$ thickness and from the same cold-rolled of $2 \mathrm{~mm}$ thickness of $45 \mathrm{~mm}$ wide and $300 \mathrm{~mm}$ long. Holes with a diameter of $22 \mathrm{~mm}$ were made to set the samples in the same frame insulators, which were used for the previous tests [17] (Figure 1). 
The superficial preparation was the sanding up to Sa3 grade of SIS 055900 standard (1967) and weighing the samples. Three samples exposed at 3, 6, 9, 12 , $18,24,30,36,42,48$, and 60 months were removed each time, and after measuring their electrochemical potential in situ [18] they were weighed (increased weight).

Besides there are samples which were exposed during 35 years and the results were obtained by optical microscopy, electron scanning, and electron probe microanalysis, following the same techniques which were applied to the ones samples exposed during 60 months.

Then, an acid pickling was carried out at $80^{\circ} \mathrm{C}$ in a $\mathrm{HCl}$ solution $(50 \%)$ with urotropine $(0.1 \%)$ as inhibitor of the steel attack. The samples were weighted at intervals of 10 minutes each until achieving almost linear weight variations between 30 and 50 minutes, according to DP/8407 ISO standard. The $\Delta \mathrm{W}(\mathrm{g})$ value was determined by the intersection of the line obtained by linear regression by minimum squares with the vertical axis (Figure 2) [19].

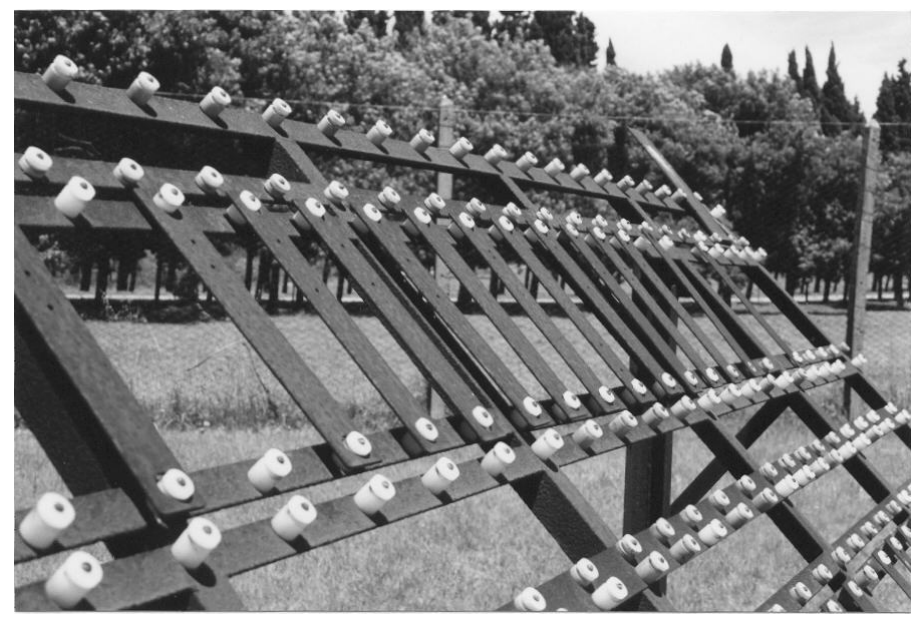

Figure 1: $\quad$ PA steel outdoor test in Villa Martelli urban site.

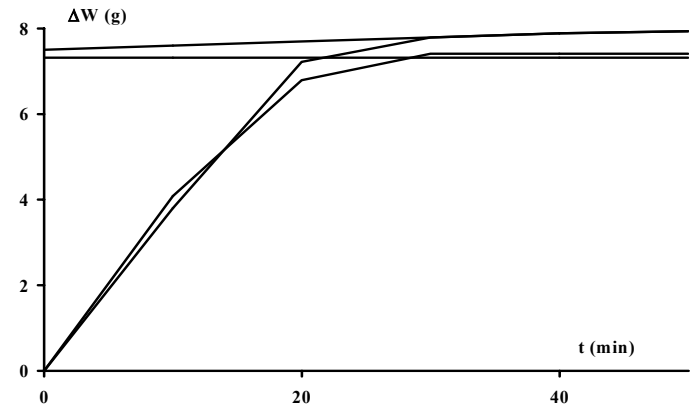

Figure 2: Weight loss based on pickling time, and pertinent linear regression. 
Three hot-rolled PA steel specimens exposed for 5 years in Villa Martelli station. The results were graphically represented from (1).

$$
\Delta W=k \cdot t^{n}
$$

$\mathrm{k}$ and $\mathrm{n}$ constants were determined from experimental data by regression analysis; results are shown in Table 2 .

Table 2: $\quad \mathrm{k}$ and $\mathrm{n}$ constants of the linear regression.

\begin{tabular}{|c|c|c|c|}
\hline Steel & Thickness & & Urban Site \\
\hline PA H.R. & \multirow{2}{*}{$3 \mathrm{~mm}$} & $\mathrm{k}$ & 1.2177 \\
\cline { 3 - 4 } & & $\mathrm{n}$ & 0.1652 \\
\hline \multirow{2}{*}{ PA C.R. } & $2 \mathrm{~mm}$ & $\mathrm{k}$ & 1.9232 \\
\cline { 3 - 4 } & & $\mathrm{n}$ & 0.3641 \\
\hline
\end{tabular}

$\mathrm{n}$ exponent values for hot-rolled PA steel are lower than Cor Ten A values and QST 52 non-weathering steel values, which were determined in previous tests [17] (Figure 3).

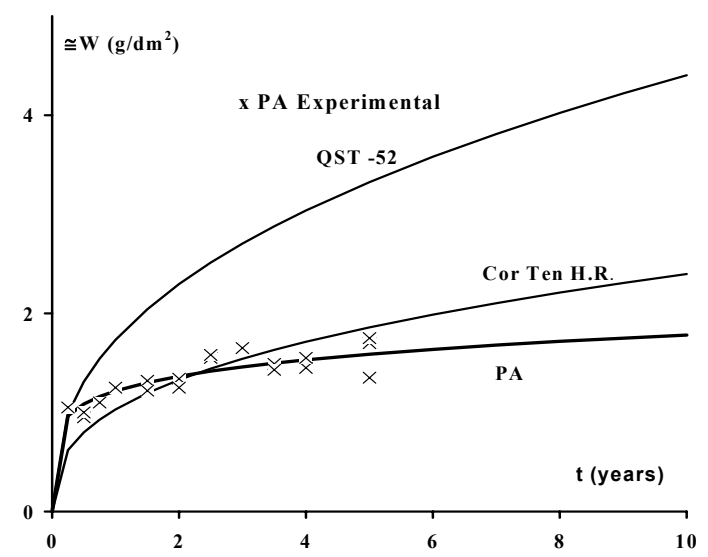

Figure 3: Time-based weight loss of hot-rolled PA steel, extrapolated at 10 years. Urban site.

Figures 4 to 7 show the $\Delta \mathrm{W}(\mathrm{g})$ weight loss on the basis of the weight of the corrosion products that form the patina as well as the line of experimental data obtained by linear regression in Villa Martelli urban site. In those same figures, we can see two lines passing through the coordinate origin, which correspond to two extreme cases of patina chemical composition. If all the Fe dissolved in the corrosive process had combined and formed $\mathrm{FeOOH}$, the representative points would have met on the lowest slope line; if it had been fully combined forming magnetite, they would have met on the highest slope line with respect to the horizontal axis. 

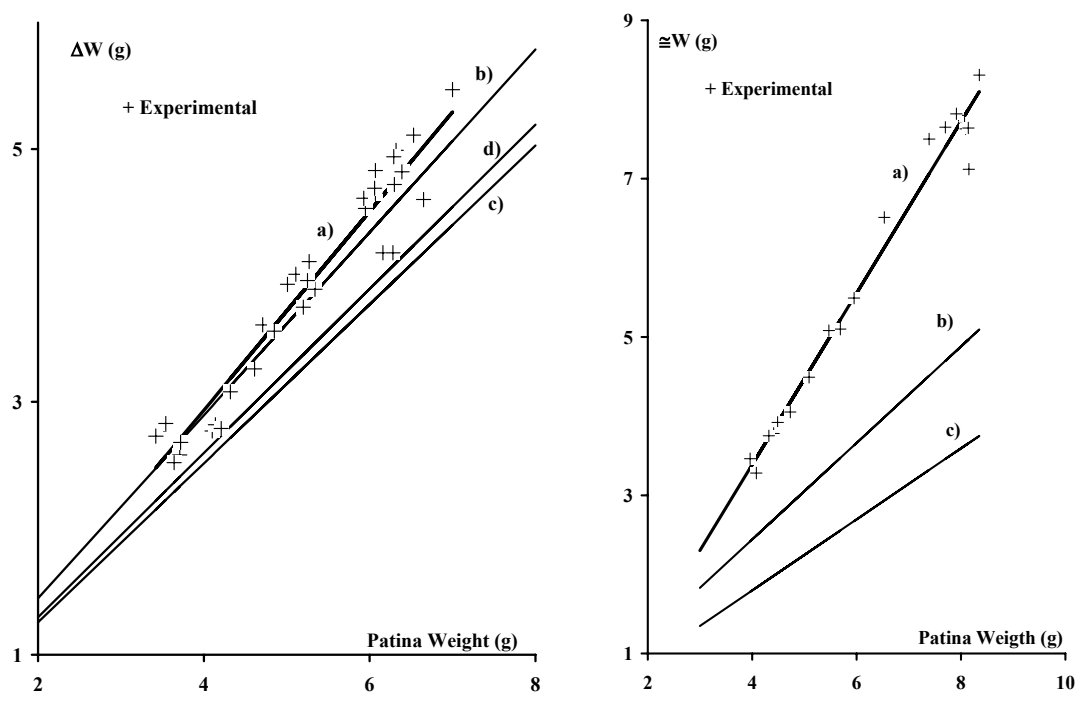

Figure 4: Hot-rolled PA steel in Figure 5: Cold-rolled PA steel urban site:
a) Regression;
b) $\mathrm{Fe}_{3} \mathrm{O}_{4}$
c) $\mathrm{FeOOH}$;
d) $0.925 \mathrm{FeOOH}+0.075$ $\mathrm{Fe}_{3} \mathrm{O}_{4}$. in urban site:
a) Regression;
b) $\mathrm{Fe}_{3} \mathrm{O}_{4}$;
c) $\mathrm{FeOOH}$.

Since a mixture of the two compounds forms the patinas, the representative points should meet in the area between these two boundaries.

The abscissa difference between the line resulting from linear regression of experimental data, and the lines pertaining to $\mathrm{Fe}_{3} \mathrm{O}_{4}$ and $\mathrm{FeOOH}$ gives us the extreme values of the corrosion products weight loss by rain wash. If we compare this experimental result with the results of the hot-rolled Cor Ten A steel and QST - 52 steel (Figures 7 and 8) [17], we will notice that there is a decrease of the corrosion products that are let loose among PA steel, Cor Ten A steel and non-weathering steel, when they are exposed to the open air.

The metal weight swept away by dew or rain-wash may be estimated as follows:

The abscissa difference between the line obtained by regression from $\Delta \mathrm{W}(\mathrm{g})$ experimental data, and the one corresponding to the FeOOH line $\left(\mathrm{W}_{\mathrm{c}}(\mathrm{g})\right)$-as the most unfavourable case- represents the weight loss by $\Delta \mathrm{W}_{\mathrm{L}}$ wash:

$$
\Delta \mathrm{W}_{\mathrm{L}}=\mathrm{W}_{\mathrm{c}}-\mathrm{W}_{\mathrm{P}}
$$

Considering as abscissas the previous ordinates and vice versa:

$$
\Delta \mathrm{W}_{\mathrm{L}}=\left(\mathrm{b}_{\mathrm{c}}-\mathrm{b}_{\mathrm{P}}\right) \Delta \mathrm{W}
$$


where:

$b_{c}$ : Angular coefficient with respect to the $\Delta \mathrm{W}(\mathrm{g})$ vertical axis of the $\mathrm{FeOOH}$ line.

$\mathrm{b}_{\mathrm{p}}$ : Angular coefficient with respect to the $\Delta \mathrm{W}(\mathrm{g})$ vertical axis of the line obtained by regression from experimental data.

$\Delta \mathrm{W}(\mathrm{g})$ : Weight loss of the specimens.

According to (1)

$$
\Delta W\left(\frac{g}{d m^{2}}\right)=\frac{\Delta W(g)}{A\left(d m^{2}\right)}=k \cdot t^{n} \quad \begin{aligned}
& \mathrm{k} \text { and } \mathrm{n}: \text { Regression coefficients. } \\
& \text { They depend on the outdoor } \\
& \text { exposure site and the material. } \\
& \text { Substituting (2) }
\end{aligned}
$$

$$
\Delta \mathrm{W}_{\mathrm{L}}=\left(\mathrm{b}_{\mathrm{c}}-\mathrm{b}_{\mathrm{p}}\right) \cdot A \cdot \mathrm{k} \cdot \mathrm{t}^{\mathrm{n}}=\mathrm{K} \cdot \mathrm{t}^{\mathrm{n}}
$$

The values for the calculus are shown in Table 2, and results are shown in Figure 8 .
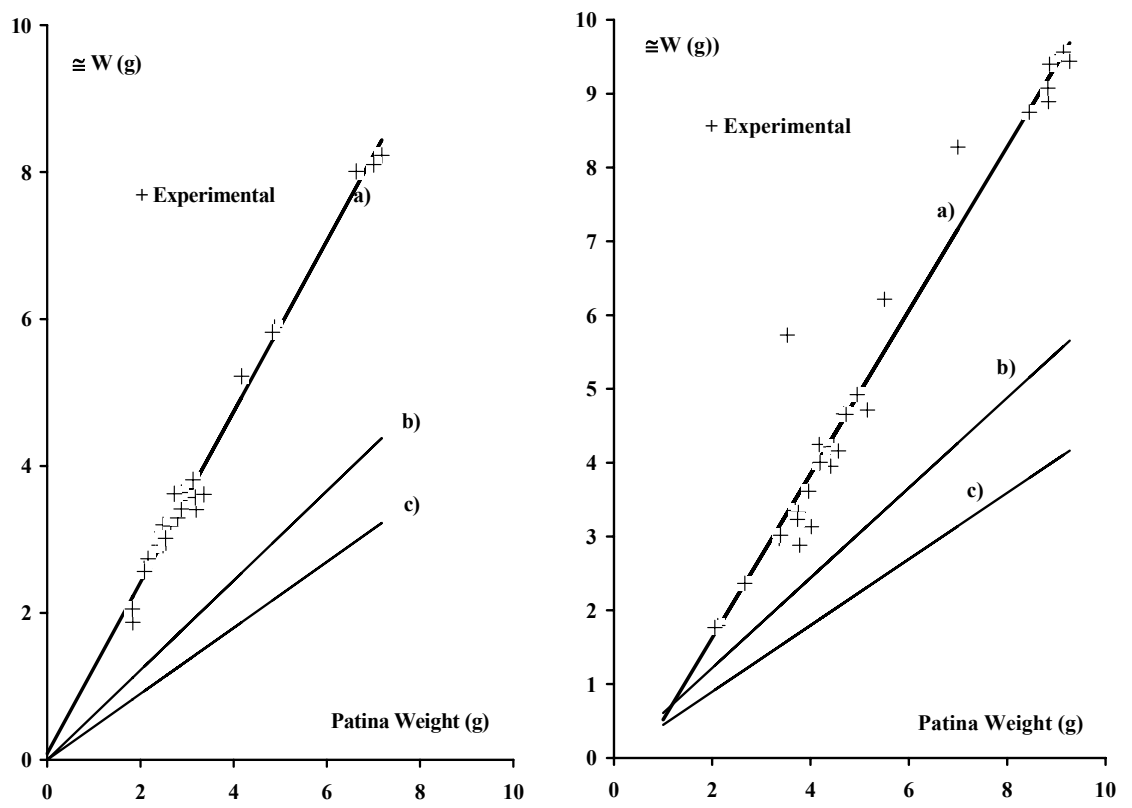

Figure 6: Hot-rolled Cor Ten A Figure 7: Hot-rolled QST - 52 steel steel in urban site:
a) Regression;
b) $\quad \mathrm{Fe}_{3} \mathrm{O}_{4}$
c) $\mathrm{FeOOH}$.
a) Regression;
b) $\quad \mathrm{Fe}_{3} \mathrm{O}_{4}$;
c) $\mathrm{FeOOH}$.

in urban site: 
Table 3: $\quad$ Values for the graphic representation of (3) and (4).

\begin{tabular}{|c|c|c|c|c|c|c|c|}
\hline Steel & $\mathbf{k}$ & $\mathbf{n}$ & $\mathbf{A}\left(\mathbf{d m}^{2}\right)$ & $\mathbf{b}_{\mathbf{c}}$ & $\mathbf{b}_{\mathbf{p}}$ & $\mathbf{K}$ & $\mathbf{n K}$ \\
\hline & \multicolumn{7}{|c|}{ Urban Site } \\
\hline PA. H.R. & 1.2173 & 0.1652 & 2.87 & 1.5910 & 1.2834 & 1.0746 & 0.1775 \\
\hline PA. C.R. & 1.9232 & 0.3641 & 3.01 & 1.5910 & 0.9522 & 3.6979 & 1.3664 \\
\hline $\begin{array}{c}\text { Cor Ten } \\
\text { A H.R. }\end{array}$ & 1.2734 & 0.1901 & 3.00 & 1.5910 & 0.8598 & 0.8598 & 0.5310 \\
\hline
\end{tabular}
H.R.: Hot-rolled
C.R.: Cold-rolled

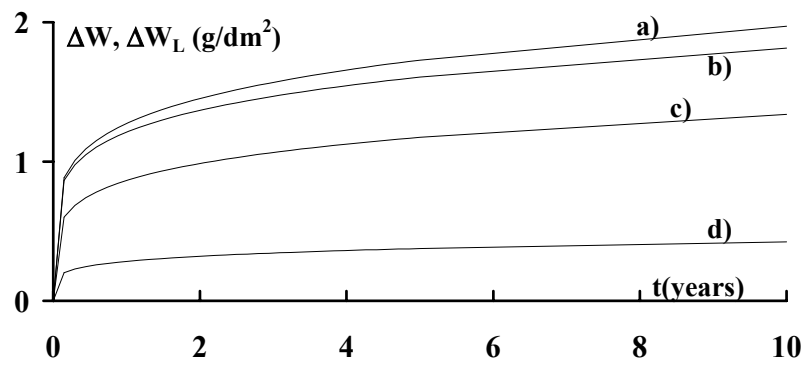

Figure 8: Comparison between the total weight loss and the corresponding one to dew and/or rain-wash in Villa Martelli urban site. a) $\Delta \mathrm{W}$ Cor Ten A; b) $\Delta$ W PA H.R; c) $\Delta \mathrm{W}_{\mathrm{L}}$ Cor Ten A; d) $\Delta \mathrm{W}_{\mathrm{L}}$ PA H.R..

The variation of the weight loss by $\Delta \mathrm{W}_{\mathrm{L}}$ wash with respect to time is expressed by the function derivative (4):

$$
\frac{d}{d t} \Delta W_{L}=n K t^{(n-1)}
$$

as shown in Figure 9.

\section{Corrosion potential "In-situ” measurements [20]}

The purpose of this technique is to use a non-destructive methodology to evaluate the corrosion product characteristics, which are formed on steels in the open air.

An agar $\mathrm{KCl}$ bridge-electrode holder is used to set the calomel-saturated reference electrode, and also potential recording equipment, a millivoltmeter or high impedance recorder. As the name says, it can be used to record the potential evolution of the specimens exposed to the open air, without removing them from the site.

In order to establish the electric continuity, on the corners of the sample is polished as little as possible on both sides, and contact is made through a small 
clamp, wire and plug to the recording equipment. The other equipment input is connected to the calomel-saturated reference electrode, which has been already set in the agar $\mathrm{KCl}$ bridge-electrode holder. The electrode holder open bottom is specimen area, whose corrosion potential or open circuit $(\mathrm{Ec})$ we wish to measure. This is done in three different spots of the specimen starting 10 minutes upon the circuit is closed. Readings every 30,60 and 90 seconds are recorded keeping the electrode holder in contact with every area of the specimen to measure. Te potential is the result of the readings average at a same interval in the three chosen areas of the sample.

In the case of the Cor Ten A weathering steel exposed at Villa Martelli outdoor test station for 15 years, the value obtained was $+217 \mathrm{mV}_{\text {sce }}$ same value as the one given by Pourbaix [18] for well weathered steels in industrial sites. According to the same technique the average value of 3 samples at 35 years is + $150 \mathrm{mV}_{\text {sce. }}$.

\section{Conclusions}

Based on the long lasting time experimental results, 35 years, the conclusions are that a formulation containing the necessary microalloying elements $(\mathrm{Cu}, \mathrm{Cr}$, and $\mathrm{Si}$ ) produces a protective corrosion film of the steel.

Experimental samples of P.A. steel were tested outdoors in an Urban Site exposure which produced a very effective passive patina. This aim was achieved through an increase of a non-metallic inclusions density with spherical morphology, great chemical reactivity and very small size of them.

Non-metallic inclusions modified by rare earth additions, particularly $\mathrm{Ce}$, was considered to join: weatherability and better mechanical properties.

The outdoor tests were carried out during 35 years. The results were obtained by optical microscopy, electron scanning, and electron probe microanalysis showing that the addition of microalloyed elements modifies steel behaviour. This modification means a steel increase resistance towards atmospheric corrosion.

\section{References}

[1] P. Merino, A. Sanchez, and E. Porto. Mapas de España de corrosividad atmosférica. CYTED, p. 319, 1993.

[2] E. Klund. Scandinavian Journal of Metallurgy p. 331, 1972.

[3] A. Szummer and M. Janik - Czachor, Werkstoffe und Korrosion, 33, p.150, 1982.

[4] M. Pourbaix. Corrosion Sci, Vol. 12. 1972.

[5] M. Pourbaix and L. de Miranda. In passivity and its breakdown on iron and iron base alloys. NACE, p. 47, 1976.

[6] K. Bohnenkamp. Tribune du CEBEDAU. Tech. Rep. 324, 1970.

[7] T. Mizawa etal. Corrosion Sci, Vol. 11. 1971.

[8] I. Suzuki, N. Masuko, and Y. Hisamatsu. Corrosion Sci, vol. 19. No. 8. 1979. 
[9] T. Moroishi. Transaction ISIJ Sci, Vol. 11. 1971.

[10] M. Stratmann, K. Bohnenkamp, and J. Engell. Corrosion Sci, Vol. 23. No. 9. 1983.

[11] K. Inouye et al. Corrosion Sci, vol. 16. 1976.

[12] B. M. Rosales. Superficial films behaviour during atmospheric corrosion. Scientific Meeting on Fe Physicochemical and its Oxides, August 1986.

[13] H. Kihira, S. Ito, and T. Murata. Corrosion Sci, Vol. 45. No. 4. 1989.

[14] E.S. Ayllón, ELECTROCOR 2007, Wit Transactions on Engineering Sciences, Vol 54, p. 329-338, 2007.

[15] R. Zenarruja, H: Moral, H. Spira, G. Waellkens, E. Ribera, A. Borras, L. Ferro and H. Reggiardo, Comité de Acería (Steel Mill Committee), IAS, Chapter 2, p.55, 1983.

[16] B.M. Rosales and. M.C. Leiro, Jornadas SAM'95, Córdoba, Argentina, p. 295, May 16-20, 1995.

[17] E.S. Ayllón, S.L. Granese and B.M. Rosales, Corrosion Reviews, 9, № 3-4, p. 245, 1990.

[18] M. Pourbaix, Rapports Techniques, CEBELCOR, 109, R.T. 160, 1969.

[19] A. Fernández, J.A. Navarro and B.M. Rosales, Proc. $4^{\circ}$ Congreso Iberoamericano de Corrosión y Protección, (4 ${ }^{\circ}$ Latin American Congress on Corrosion and Protection), Mar del Plata, Argentina, 1, p.143, October 25-30, 1992.

[20] E. Ayllón, Microalloyed steels resistant to atmospheric corrosion, WIT Press Southampton, Boston, p. 29, 2005. 